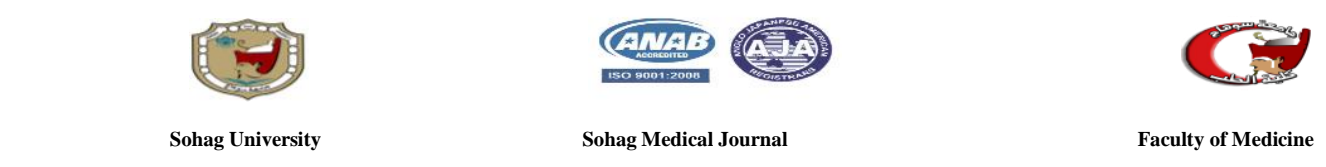

\title{
Prognostic value of central venous oxygen saturation during anesthesia for cardiac surgery.
}

\author{
Abdelrahman Hassan, Khaled Mohamed Hassan, AbdelHady \\ Ahmad Helmy, Marwa Ahmad Mahrous
}

Department of Anesthesiology, Faculty of Medicine, Sohag University

\begin{abstract}
Background:During cardiac surgery, CPB machine pumps blood instead of the heart affecting blood flow and hence blood perfusion of all tissues. One important marker of blood perfusion is central venous oxygen saturation. Relationship between central venous oxygen saturation and patient morbidity and mortality is an indicator for the reliability of blood lactate as a perfusion marker.
\end{abstract}

Objectives: This study aimed to assess the value of monitoring of central venous oxygen saturation in postoperative prognosis. The primary outcome was ICU length of stay, while the secondary outcomes were both duration of mechanical ventilation and postoperative complications.

Methods: In a prospective observational study, 66 patients admitted to Sohag university hospital and Sohag Heart Institute in the period between October 2017 and April 2019 for open cardiac surgery were enrolled. Immediately after induction of anesthesia, the first sample of venous blood gas was obtained from central venous catheter. For measuring of central venous oxygen saturation, the next samples were obtained just before CPB weaning, the next after 24 hours of staying ICU and the last sample were obtained after 48 hours of staying ICU.

Results: Central venous oxygen saturation in correlation to ICU length of stay showed patients stayed in the ICU less than 48 hours had significant p-value $<0.001$ and patients stayed in the ICU more than 48 hours had a non-significant p-value 0.693 indicating more significant change in central venous oxygen saturation in patients with favorable outcome. Central venous oxygen saturation in correlation to postoperative duration of mechanical ventilation showed patients stayed on mechanical ventilation less than 12 hours had significant p-value 0.004 and patients stayed on mechanical ventilation more than 12 hours had a non-significant p-value 0.724 indicating more significant change in central venous oxygen saturation in patients with favorable outcome. Central venous oxygen saturation in correlation to postoperative complications showed patients without postoperative complications had significant p-value 0.001 and patients with postoperative complications had a non-significant $\mathrm{p}$-value 0.436 indicating more significant change in central venous oxygen saturation in patients with favorable outcome.

Conclusion: Measuring ScvO2 at 4 points during and after open-heart surgery showed their prognostic value, regarding results for ScvO2: ICU length of stay, duration of mechanical ventilation and complications.

Keywords: ScvO2, Cardiac Surgical Procedures, prognosis. 


\section{Introduction:}

identifying predictors of morbidity and mortality is of great importance during management of patients of cardiac surgery. Morbidity and mortality depend mainly on the patient status in the preoperative period, both also depend on the specific anesthetic, surgical, and postoperative factors. Tissue perfusion markers in the form of central venous oxygen saturation and blood lactate, therefore, are of great significance during the management of these patients $(1,2)$. So monitoring tissue perfusion adequacy during $\mathrm{CPB}$ is necessary by certain parameters and adjusting the hemodynamic parameters according to the changing parameters. Central venous oxygen saturation (ScvO2) considered as another marker for tissue hypoperfusion detection and can be measured from a central venous catheter (CVC) which is less invasive and less costly compared to pulmonary artery catheter (PAC). Some studies have evidenced that $\mathrm{ScvO} 2$ is sufficient equality to $\mathrm{SvO} 2(3,4)$. $\mathrm{ScvO} 2$ more than $75 \%$ is generally considered within normal (5), where the demand for oxygen equals $25 \%$ of total availability. If oxygen demand increased, it can be met either by increasing delivery or by increasing the extraction of oxygen from the hemoglobin molecule. Extraction rate more than $50 \%$ means increased risk of regional tissue hypoxia (6). Here in our study we are testing the relationship between central venous oxygen saturation and postoperative ICU length of stay as a primary goal and both postoperative duration of mechanical ventilation and complications as secondary goals.

\section{Patients and methods:}

Patients: Sixty six ASA II (American Society of Anesthesiologists) patients aged above 18 years old scheduled for open heart surgery, were included in this prospective observational study which was performed in Sohag university hospital and in Sohag
Heart Institute in the period between October 2017 and April 2019 after local ethics committee approval and informed consent for each patient was obtained to be included in the study.

Demographic data: Age, sex, weight and height of all patients were collected.

Exclusion criteria:* Pediatrics patients. * Surgery in an emergency situation e.g. procedures for ascending or descending thoracic aorta, resection of left ventricular aneurysm.* Pregnant patients.*Cancer patients.*Patients with hepatic dysfunction.*Patients with an abnormal (> $2 \mathrm{mmol} / \mathrm{l})(<18 \mathrm{mg} / \mathrm{dl})$ plasma lactate value before induction of anesthesia.

Preoperative: Patients were evaluated preoperatively as regard: Detailed history taking, Thorough clinical examination, Laboratory investigations including complete blood picture, electrolytes, kidney, liver function, ECG, echocardiography, risk factors e.g: hypertension, diabetes, stroke, etc, were also checked.

Intraoperative: Insertion of two large-bore I.V. cannula (18 gauge), arterial line, premedication (given in the holding area before pushing patient inside OR): with midazolam $15 \mathrm{mg}$ over two minutes, Induction: was done with propofol $2 \mathrm{mg} / \mathrm{kg}$, succinylcholine $1.5 \mathrm{mg} / \mathrm{kg}$, fentanyl 500 mcg, Maintainance: by isoflurane, pancuronium $0.01 \mathrm{mg} / \mathrm{kg}$. intubation and mechanical ventilation was standardized for all patients(according to Sohag heart institute protocol). Monitoring: a radial or femoral artery catheter for invasive measurement of arterial blood pressure and intermittent blood sampling, an internal jugular catheter, and esophageal probe for temperature monitoring, Patients were monitored by a pulse oximeter, capnography, electrocardiography and activated clotting time were all monitored. A Foley's catheter was inserted for urine output 
monitoring. Hemodynamics was maintained by Inotropes and vasodilators in the form of dobutamine, adrenaline, noradrenaline, and nitroglycerine as indicated. Volume replacement was done with Ringer's acetate, colloid, and packed RBCs. The intraoperative total dose of inotropes and /or vasopressors was also calculated. Procedure: injection of 300 IU/kg (10) of unfractionated heparin and measuring activated clotting time which should be longer than 450 seconds before Cardiac cannulation which was done later. Additional boluses of heparin were used to maintain an activated clotting time in the normal range before and during CPB. All patients were treated with the same $\mathrm{CPB}$ technique and non-pulsatile CPB initiated. The bypass circuit was primed with Ringer's acetate to make the priming volume 1500 $\mathrm{ml}$. Standard cardiopulmonary bypass techniques with systemic hypothermia of $28-32^{\circ} \mathrm{C}$ were used. Cardiac arrest was obtained and maintained by using antegrade intermittent blood cardioplegia, also custodiol (dose: one bottle for each case) and retrograde cardioplegia used in $\mathrm{CABG}$. Extracorporeal circulation with the flow of pump of $2.0-2.4 \mathrm{~L} / \mathrm{min} / \mathrm{m} 2$ of body surface area. Monitoring of the mean arterial pressure was $\mathrm{m}$ continuous and it was maintained between 50 and $60 \mathrm{mmHg}$ during $\mathrm{CPB}$. Myocardial protection was achieved with intermittent antegrade cold blood cardioplegia \{St Thomas I solution\}, dose of $15 \mathrm{ml} / \mathrm{kg}$, repeated in $30-35 / \mathrm{min}$ intervals or as requested by the surgeon. After completion of the CPB and removal of the cannulas, heparin was reversed by using protamine sulfate at a $1: 1.5$ ratio. The duration of CPB was defined as the total elapsed time from the institution of CPB until discontinuation of $\mathrm{CPB}$ at the end of surgical repair. Clamp time and reperfusion time were calculated.
Postoperative: Patients were transmitted to the intensive care unit mechanically ventilated. In the intensive care unit patient was ventilated electively with monitoring of hemodynamic parameters and arterial blood gases. We attempted to maintain normotensive and normovolemic hemodynamic status. Postoperative management after cardiac surgery is standardized according to Sohag heart institute protocol. When hypovolemia occurred it was treated by crystalloids infusion or blood transfusion maintaining hemoglobin (HB) level is $>8 \mathrm{~g} / \mathrm{dL}$ and/or hematocrit of $>25 \%$. When hemodynamic support is indicated, dobutamine (2.5$10 \mu \mathrm{g} / \mathrm{kg} / \mathrm{min})$, norepinephrine $(0.03-0.2$ $\mu \mathrm{g} / \mathrm{kg} / \mathrm{min}$ ), and milrinone dosed at a 50 $\mu \mathrm{g} / \mathrm{kg}$ loading dose and $0.5 \mu \mathrm{g} / \mathrm{kg}$ per minute maintenance infusion are all used as inotropic support(according to the situation). Sampling: Samples were collected from the central venous line for analysis of serum lactate (mg) level and $\mathrm{ScvO}_{2} \%$ in the following points: 1.Just after induction of anesthesia, 2.Just before CPB weaning 3 . After 24 hours postoperative 4.After 48 hours postoperative, Samples were analyzed using standard arterial blood gas analyzer (GEM Premier 3000 Blood Gas Analyzer).

Statistical analysis: The data Categorical variables were described by number and percent $(\mathrm{N}, \%)$, where continuous variables described by the mean and standard deviation (Mean, \pm SD). Chi-square test and Fisher exact test used to compare categorical variables where the comparison between continuous variables by t-test and ANOVA. A p-value $<0.05$ was considered statistically significant. All analyses were performed with the IBM SPSS 20.0 software.

\section{Results:}

The mean age of the patients was $50 \pm 15$ years old. Men percentage versus women percentage was $56 \%$ and $44 \%$ respectively. 


\begin{tabular}{|l|l|l|}
\hline Variable n=66 & Range & Mean \pm SD \\
\hline Age $($ years $)$ & $18-77$ & $50.39 \pm 15.05$ \\
\hline Sex: & M: $37(56 \%)$ & F: $29(44 \%)$ \\
\hline Weight $(\mathrm{kg})$ & $44-116$ & $74.94 \pm 15.99$ \\
\hline Height $(\mathrm{cm})$ & $140-175$ & $158.29 \pm 9.51$ \\
\hline BMI $(\mathrm{kg} / \mathrm{m} 2)$ & $19.3-46.46$ & $29.88 \pm 5.79$ \\
\hline
\end{tabular}

Table (1) demographic data for age \&gender and body mass index
Central venous oxygen saturation in correlation to ICU length of stay showed patients stayed in the ICU less than 48 hours had significant p-value $<0.001$ and patients stayed in the ICU more than 48 hours had a non-significant p-value 0.693 indicating more significant change in central venous oxygen saturation in patients with favorable outcome

\begin{tabular}{|l|l|l|l|l|l|}
\hline $\begin{array}{l}\text { ScvO } \\
\text { n=66 }\end{array}$ & Induction & Bypass & After $24 \mathrm{~h}$ & After $48 \mathrm{~h}$ & \multirow{2}{*}{ P. value } \\
\cline { 2 - 6 } & Mean \pm SD & Mean \pm SD & Mean \pm SD & Mean \pm SD & \\
\hline $\begin{array}{l}\text { Less than 48 } \mathbf{h} \text { Icu } \\
\text { length of stay }\end{array}$ & $\mathbf{8 1} \pm \mathbf{5 . 0 7}$ & $\mathbf{7 4 . 6 1} \pm \mathbf{8 . 3 4}$ & $\mathbf{7 1 . 4 8} \pm \mathbf{1 7 . 5 7}$ & $\mathbf{7 8 . 2 3} \pm 15.5$ & $<\mathbf{0 . 0 0 1 * *}$ \\
\hline $\begin{array}{l}\text { More than 48 } \mathrm{h} \text { Icu } \\
\text { length of stay }\end{array}$ & $\mathbf{7 7 . 3 3} \pm \mathbf{4 . 9 2}$ & $\mathbf{7 4 . 8 3} \pm \mathbf{6 . 3 2}$ & $\mathbf{8 1 . 1 7} \pm \mathbf{1 9 . 1 9}$ & $\mathbf{7 9 . 1 7} \pm \mathbf{1 6 . 8 5}$ & $\mathbf{0 . 6 9 3}$ \\
\hline
\end{tabular}

Table (2):

$\mathrm{ScvO} 2$ and ICU length of stay

group, 2 patients died after 2, 3 hours postoperative. relation to number of hours on mechanical ventilation with the range of hours in each

\begin{tabular}{|l|l|l|}
\hline \multirow{2}{*}{$\begin{array}{l}\text { Vent. Hour }(\text { number of } \\
\text { patients) }\end{array}$} & \multicolumn{2}{|c|}{ Ventilation duration in hours } \\
\cline { 2 - 3 } & Range & Mean \pm SD \\
\hline Vent $>12 \mathrm{~h}(\mathrm{n}=8)$ & $14-48$ & $32.13 \pm 15.9$ \\
\hline Vent $<12 \mathrm{~h}(\mathrm{n}=\mathbf{5 6})$ & $2-12$ & $6.62 \pm 2.24$ \\
\hline
\end{tabular}

Table (3): 12 hours ventilation

Vent=ventilation
Central venous oxygen saturation in correlation to postoperative duration of mechanical ventilation showed patients stayed on mechanical ventilation less than 12 hours had significant p-value 0.004 and patients stayed on mechanical ventilation more than 12 hours had a non-significant $\mathrm{p}$ value 0.724 indicating more significant change in central venous oxygen saturation in patients with favorable outcome.

\begin{tabular}{|c|c|c|c|c|c|c|}
\hline \multirow{2}{*}{$\begin{array}{l}\mathrm{ScvO}_{2} \% \\
\mathrm{n}=66\end{array}$} & Induction & Bypass & After $24 \mathrm{~h}$ & After 48 h & \multirow{2}{*}{ P. value } & \multirow{4}{*}{$\begin{array}{l}\text { Table (4): } \\
\text { ScvO2 and } \\
\text { duration of } \\
\text { mechanical } \\
\text { ventilation }\end{array}$} \\
\hline & $\operatorname{Mean} \pm$ SD & Mean \pm SD & Mean \pm SD & Mean \pm SD & & \\
\hline $\begin{array}{l}\text { Less than } 12 \mathrm{~h} \text { Duration } \\
\text { of mechanical ventilation }\end{array}$ & $80.09 \pm 5.03$ & $74.52 \pm 8.29$ & $72.82 \pm 17.82$ & $79.07 \pm 14.26$ & $0.004 * *$ & \\
\hline $\begin{array}{l}\text { More than } 12 \mathrm{~h} \text { Duration } \\
\text { of mechanical ventilation }\end{array}$ & $83 \pm 6.07$ & $77.38 \pm 4.96$ & $76.63 \pm 21.16$ & $73.75 \pm 23.91$ & 0.724 & \\
\hline
\end{tabular}

This table shows number of patients with and without complications and types of complications occurred. Two patients died after 6,10 hours postoperative and one patient died after48 hours postoperative. 


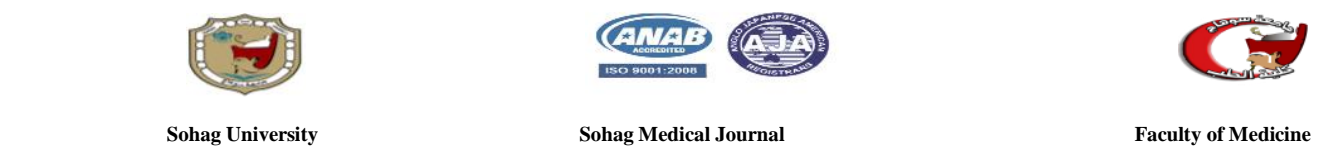

\begin{tabular}{|l|l|l|}
\hline Complications & No. & $\%$ \\
\hline No & 54 & $\mathbf{8 1 . 8 2}$ \\
\hline Yes & 12 & $\mathbf{1 8 . 1 8}$ \\
\hline Arrhythmia & 6 & $\mathbf{9}$ \\
\hline Convulsions & 1 & 1.52 \\
\hline $\begin{array}{l}\text { Disturbed conscious } \\
\text { level }\end{array}$ & 1 & 1.52 \\
\hline Bleeding and reopen & 2 & $\mathbf{3 . 0 3}$ \\
\hline
\end{tabular}

Table (5): Recorded complications in our study

Central venous oxygen saturation in correlation to postoperative complications showed patients without postoperative complications had significant $\mathrm{p}$-value 0.001 and patients with postoperative complications had a non-significant $\mathrm{p}$-value 0.436 indicating more significant change in central venous oxygen saturation in patients with favorable outcome.

\begin{tabular}{|c|c|c|c|c|c|}
\hline \multirow{2}{*}{$\begin{array}{l}\mathrm{ScvO}_{2} \% \\
\mathrm{n}=66\end{array}$} & Induction & Bypass & After $24 h$ & After $48 \mathrm{~h}$ & \multirow{2}{*}{ P. value } \\
\hline & Mean \pm SD & $\operatorname{Mean} \pm$ SD & Mean \pm SD & Mean \pm SD & \\
\hline $\begin{array}{l}\text { No } \\
\text { Complications }\end{array}$ & $80.53 \pm 5.15$ & $74.75 \pm 8.48$ & $72.85 \pm 18.08$ & $80.2 \pm 13.6$ & $0.001 * *$ \\
\hline $\begin{array}{l}\text { Yes } \\
\text { Complications } \\
\end{array}$ & $79.36 \pm 5.64$ & $74.18 \pm 4.94$ & $75.7 \pm 19.16$ & $68.7 \pm 22.28$ & 0.436 \\
\hline
\end{tabular}

Table (6): $\mathrm{ScvO}_{2}$ and complications:

\section{Discussion}

In our study Central venous oxygen saturation in correlation to ICU length of stay showed patients stayed in the ICU less than 48 hours had significant p-value $<0.001$ and patients stayed in the ICU more than 48 hours had a non-significant p-value 0.693 indicating more significant change in central venous oxygen saturation in patients with favorable outcome.

Balzer et al, 2015 found that rate of mortality and complication increased in patients with $\mathrm{ScvO} 2$ above $80 \%$ in patients after cardiac surgery (7). Those authors stated that the most important results in their study were that a supposed safe initial ScvO2 above $80 \%$ patients had the highest in-hospital mortality and the highest mortality in a 3-year follow-up (7). Balzer, et al., 2015 showed a supposed safe initial ScvO2 above $80 \%$ patients had prolonged duration of mechanical ventilation, postoperative complications in the form of severe postoperative inflammation evidenced by increased leukocyte counts and procalcitonin levels, and increased ICU length of stay in comparable with a normal ScvO2 $(60 \%$ to $80 \%)$ patients (7). Hu et al., 2012 stated that complications occurrence was significantly related to increased ICU length of stay, and patients with postoperative complications had a lower level of ScvO2 (63.9\% v 69.1\%). Though this was statistically non-significant (8). Pölönen, et al, 2000 discovered that the complication rate in patients with optimized $\mathrm{ScvO} 2$ of at least $70 \%$, was decreased during ICU treatment after cardiac surgery. Patients in the control group had decreased length of stay in the hospital and morbidity was lower at hospital discharge (9).

In our study, we found that Central venous oxygen saturation in correlation to postoperative duration of mechanical ventilation showed patients stayed on mechanical ventilation less than 12 hours had significant p-value 0.004 and patients stayed on mechanical ventilation more than 12 hours had a non-significant p-value 0.724 indicating more significant change in central venous oxygen saturation in patients with 
favorable outcome. We also found Central venous oxygen saturation in correlation to postoperative complications showed patients without postoperative complications had significant $\mathrm{p}$-value 0.001 and patients with postoperative complications had a nonsignificant $\mathrm{p}$-value 0.436 indicating more significant change in central venous oxygen saturation in patients with favorable outcome.

Balzer et al., 2015 found in their study that patients with initial ScvO2 above $80 \%$ showed the increased mechanical ventilation duration and prolonged ICU lengths of stay (7). Laine et al., 2013 stated that patients who had $\mathrm{ScvO} 2 \geq 70 \%$ also had a significant increase in the ICU LOS $(p=0.018)$, mechanical ventilation duration $(\mathrm{p}=$ 0.0001), and occurrence of major complications $\quad(\mathrm{p}=0.008)(\mathbf{1 1})$. They compared outcomes as regard low $\mathrm{ScvO} 2$, no significant differences in ICU/hospital LOS, mechanical ventilation duration, or major complications were evidenced in patients with $\mathrm{ScvO} 2<70 \%$ versus patients with $\mathrm{ScvO} 2 \geq 70 \%$. However, patients with $\mathrm{ScvO} 2 \geq 70 \%$ showed a significantly increase in ICU LOS $(\mathrm{p}=0.018)$, hospital LOS $(p=0.032)$, mechanical ventilation duration $(\mathrm{p}=0.0001)$, and increased incidence of major complications $(\mathrm{p}=$ 0.008) (11). Zante, et al., 2012 reported that the decreased ScvO2 was independently related to complications after major surgery in adults (12). Seear et al., 2008 showed that $\mathrm{ScvO} 2$ were the only postoperative measure found to have a good prediction as regard major adverse events (complications) (13). Pearse, et al. 2005 revealed that decreased $\mathrm{ScvO} 2$ was independently related to postoperative complications (14).

\section{Conclusion:}

Our study revealed that there is a strong relationship between central venous oxygen saturation and outcome of cardiac surgery. There was significant $p$-value in patients with favorable outcome which were patients stayed in ICU less than 48 hours, patients stayed on postoperative mechanical ventilation less than 12 hours and patients without complications indicating good prognostic value of central venous oxygen saturation during cardiac surgery. On the other side patients with unfavorable outcome which were patients stayed in the ICU more than 48 hours, patients stayed on postoperative mechanical ventilation more than 12 hours and patients with postoperative complications all had non significant $p$-value indicating the power of central venous oxygen saturation as a prognostic factor. We recommend follow-up serum lactate measurement during and after surgery for cardiac anesthesia for better prediction of outcome.

\section{Limitations:}

Limitations in our study were few numbers of patients as regard a prognostic study, not including patients in emergency situations; all patients were well prepared preoperatively, in addition to large scope of outcomes.

\section{References}

1. Leavy JA, Weil MH, Rackow EC. " Lactate washout" following circulatory arrest. JAMA. 1988; 260:662-4

2. Weil MH, Afifi AA. Experimental and clinical studies on lactate and pyruvate as indicators of the severity of acute circulatory failure (shock). Circulation 1970;41:9891001.

3. Bortone F, Mazzoni M, Repossini A, Campolo J, Ceriani R, Devoto E, et al. Myocardial lactate metabolism in relation to preoperative regional wall motion and to early functional recovery after coronary revascularization. $\mathrm{J}$ Cardiothorac Vasc Anesth. 2003;17(4):478-85.

4. Futier E, Robin E, Jabaudon M, Guerin R, 
Petit A, Bazin JE, et al. Central venous $\mathrm{O}(2)$ saturation a nd venous-to-arterial $\mathrm{CO}(2)$ difference as complementary tools for goaldirected therapy during high-risk surgery. Crit Care. 2010;14 (5):R193

5. Shepherd SJ, Pearse RM. Role of central and mixed venous oxygen saturation measurement in perioperative care. Anesthesiology 2009; 111: 649-656.

6. Herbertson MJ, Werner HA, Russell JA, Iversen K, Walley KR. Myocardial oxygen extraction ratio is decreased during endotoxemia in pigs. $\mathbf{J}$ Appl Physiol 1995;79:479-86.

7. Balzer .F , Michael Sander, Mark Simon, Claudia Spies, Marit Habicher, Sascha Treskatsch , Viktor Mezger , Uwe Schirmer, Matthias Heringlake, KlausDieter Wernecke, Herko Grubitzsch and Christian von Heymann., High central venous saturation after cardiac surgery is associated with increased organ failure and long-term mortality: an observational crosssectional study., Critical Care (2015) 19:168 DOI 10.1186/s13054-015-0889-6

8. Hu. BeeBee Y,Greg A. Laine, MS, RPh, Suwei Wang and R. Thomas Solis, Combined Central Venous Oxygen Saturation and Lactate as Markers of Occult Hypoperfusion and Outcome Following Cardiac Surgery, Journal of Cardiothoracic and Vascular Anesthesia, Vol 26, No 1 (February), 2012: pp 52-57
9. Pölönen P, Ruokonen E, Hippelainen M, Pyhnen M, Takala J: A prospective, randomized study of goal-oriented hemodynamic therapy in cardiac surgical patients. Anesth Analg 2000, 90:1052-1059.

10. Ronald D. Miller, Lars I. Eriksson, Lee A Fleisher, Jeanine P. Wiener-Kronish, Neal H Cohen, William L. Young. Heparin as anticoagulant, chapter 67: Anesthesia For Cardiac Surgical Procedures, Miller's Anesthesia $8^{\text {th }}$ edition, vol. 2, part V, 2014.

11.Laine GA, Hu BY, Wang S, Thomas Solis R, Reul GJ Jr. Isolated high lactate or low central venous oxygen saturation after cardiac surgery and association with outcome. J Cardiothorac Vasc Anesth. 2013 Dec;27(6):1271-6

12.Zante B, Kubik M, Reichenspurner $\mathbf{H}$. Combination of high $\mathrm{ScvO}_{2}$ and hyperlactatemia as sign of microcirculation disorder in patients after cardiac surgery. Thorac cardiovasc Surg 2012;60:20.

13.Seear MD, Scarfe JC, LeBlanc JG. Predicting major adverse events after cardiac surgery in children. Pediatr Crit Care Med 2008;9:606-11.

14.Pearse R, Dawson D, Fawcett J, Rhodes A, Grounds RM, Bennett ED: Changes in central venous saturation after major surgery, and association with outcome. Crit Care 2005 a, 9:R694. 